\title{
Modification of Exhaust Using Low Precious Metals for Two Wheelers
}

\author{
S. K. Vignesh ${ }^{1}$, M. Arjunan ${ }^{1}$, G. Deepan ${ }^{1}$, T. Diwakar ${ }^{1} \&$ P. Elumalai ${ }^{1}$ \\ ${ }^{1}$ Mechanical Department, Vi Institute of technology, Sirunkundram 603108, India \\ Correspondence: S. K. Vignesh, Mechanical Department, Vi Institute of technology, Sirunkundram 603108, India. \\ E-mail: Skvrajesh1995@gmail.com
}

Received: March 30, 2019

Accepted: June 26, 2019

Online Published: June 30, 2019

doi:10.5539/mer.v9n1p30

URL: https://doi.org/10.5539/mer.v9n1p30

\begin{abstract}
Toxic gases include NOX, CO, HC and Smoke which are harmful to the atmosphere as well as to the human beings. The main aim of this work is to fabricate system, where the level of intensity of toxic gases is controlled through chemical reaction to more agreeable level. This system acts itself as an exhaust system; hence there is no needs to fit separate the silencer. The whole assembly is fitted in the exhaust pipe from engine. In this work, catalytic converter with copper oxide as a catalyst, by replacing noble catalysts such as platinum, palladium and rhodium is fabricated and fitted in the engine exhaust. With and without catalytic converter, the experimentations are carried out at different loads such as $0 \%, 25 \%, 50 \%, 75 \%$, and $100 \%$ of maximum rated load. From the experimental results it is found that the maximum reduction is $32 \%, 61 \%$ and $21 \%$ for HC, Nox and CO respectively at $100 \%$ of maximum rated load when compared to that of without catalytic converter. This catalytic converter system is cash effective and more economical than the existing catalytic converter.
\end{abstract}

Keywords: catalytic converter, copper oxide, nitric acid

\section{Introduction}

A catalytic converter is a device that uses a catalyst to convert pollutants to non-pollutants of combust product in C.I. Engine. The three harmful compounds are: Hydrocarbons (formed by the unburned gasoline). Carbon monoxide (formed by the combustion of gasoline and because of disassociation at high temperature). Nitrogen oxides (created when the heat in the engine forces nitrogen in the air to combine with oxygen).

In a catalytic converter, the catalystis coated onto a ceramic honeycomb or ceramic beads that are housed in a muffler-like package attached to the exhaust pipe. The catalyst helps to convert carbon monoxide into carbon dioxide. It converts the hydrocarbons into carbon dioxide and water. It also converts the nitrogen oxides back into nitrogen and oxygen.

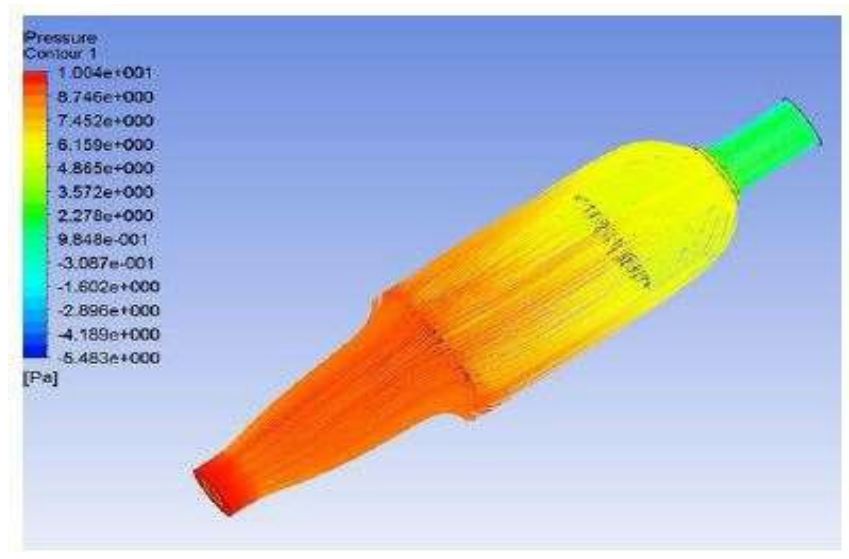

Figure 1. CFD analysis of structure 1 


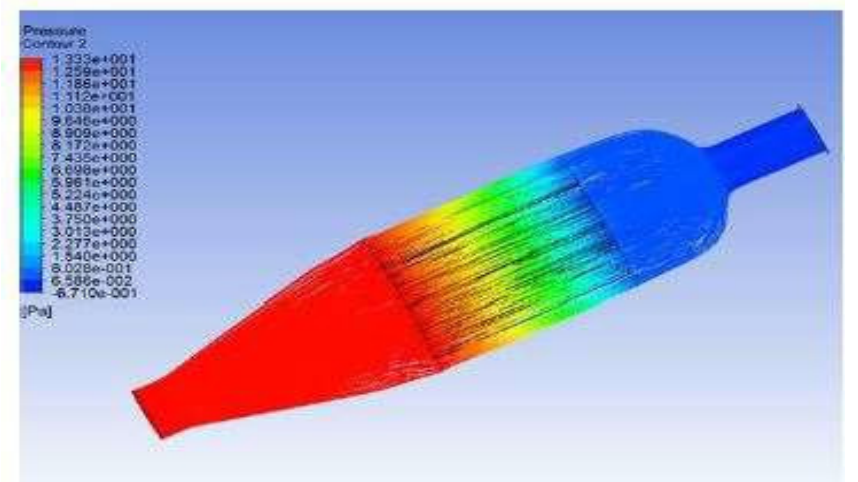

Figure 2. CFD analysis of structure 2

\section{Methodology}

1. Dismantling catalytic converter

2. Cleaning the existing catalyst and carbon deposit

3. Dip coating process

4. Applying copper oxide coating over honeycomb

5. Assembling of catalytic converter

\section{CFD Analysis}

The CFD analysis done by using ANSYS Fluent software with the exhaust pressure flow for analysis of catalytic converter.

\section{Catalytic Converter}

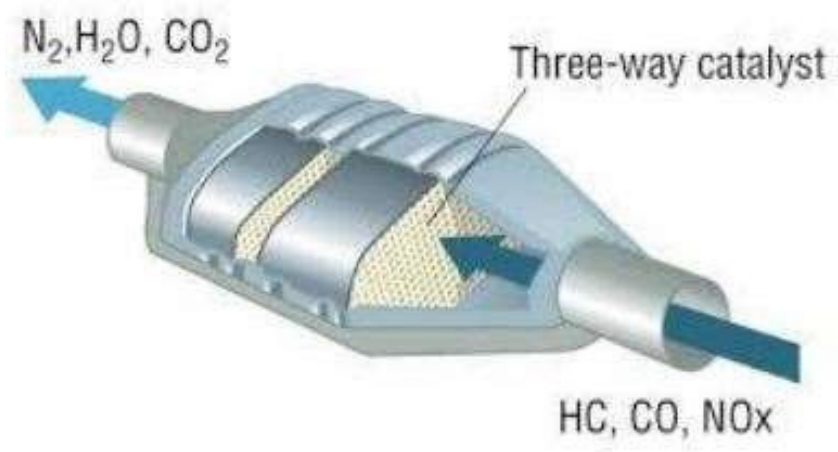

Figure 3. Typical 3 way catalytic converter

A catalytic converter is a device used to reduce the exhaust Pollutant gases from an internal combustion engine. As these precious metal usage and honeycomb structure become costliest affair, now the automobile company / after treatment device manufacturer undergoing research on alternate source on substrate and catalyst materials. In this research, we develop a no noble metal oxide based catalyst with high efficiency of catalytic activity performance as an alternative catalyst for carbon monoxide treatment emitted from vehicle emission. The catalytic converter of the present invention is made by meticulous study on literature review and in depth study about usage of alumina and its composition on catalyst material in combination with chemical reaction to reduce the $\mathrm{CO}, \mathrm{HC}, \mathrm{NOx}$.

\subsection{Types of Catalytic Convertor:}

There are two types of catalytic convertor.

1. Three-way catalytic convertor.

2. Two-way catalytic convertor.

\subsection{Catalyst Selection:}

A trial study was conducted on three types of substrates Which consisted of Nickel coated monolith substrate, Copper coated wire mesh and $\mathrm{TiO} 2$ coated wire mesh. These substrates were assembled in the converter shell and the 
emissions were measured with the help of the Gas Analyzer equipment available with the department of Mechanical Engineering at SCoE. The criterion for the selection of converter was minimum pressure drop and chaotic gas flow distribution, combined with efficient reduction values. The monolith substrate was coated with a 10 microns ${ }^{\text {ee }}$ thick layer of Nickel. Similarly, the wire mesh was coated with 15 microns thick layer of Copper. . For applying the wash coat of the $\mathrm{TiO} 2$ slurry on the wire mesh, dipping technic was used. After applying the wash coat, all the meshes were assembled in a shaft (bolt) to function as a catalyst.

\subsection{Working Principle}

A catalytic converter is a device used to reduce the toxicity of emissions from an internal combustion engine. First widely introduced on series production automobiles in the U.S. market for the 1975 model year to comply with tightening EPA regulations on auto exhaust, catalytic converters are still most commonly used in motor vehicle exhaust system. A catalyst allows chemical conversions to desired products to occur more rapidly and at lower temperatures. Automotive emissions catalytic converters consist of special combinations of precious metals such as platinum, palladium and Rhodium dispersed on high surface area carriers which in turn are coated onto the walls of ceramic or metallic monolithic structures. In the modern three-way catalytic converter, uncommuted fuel residues are oxidized with oxygen to Produce carbon dioxide and water, nitrogen oxides are converted to ubiquitous nitrogen, and toxic carbon monoxide is oxidized with oxygen to carbon dioxide.

\section{Material and Fabrication}

\subsection{Wire mesh}

It is an electrical fusion welded prefabricated joined grid consist of series of parallel longitudinal wires with accurate spacing welded across wire

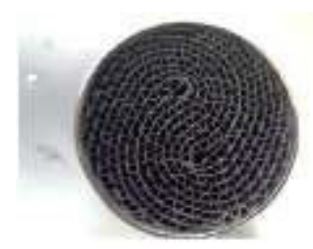

Figure 4. wire mesh struture

Wash coat- titanium oxide

It is the coating given to the substrate for the protection of catcon from various parameters

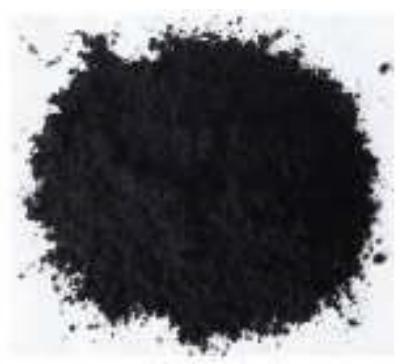

Figure 5. copper oxide

Catalyst -copper oxide + nitric acid

It is a chemical which is used to convert the toxic gases into non toxic gases. 


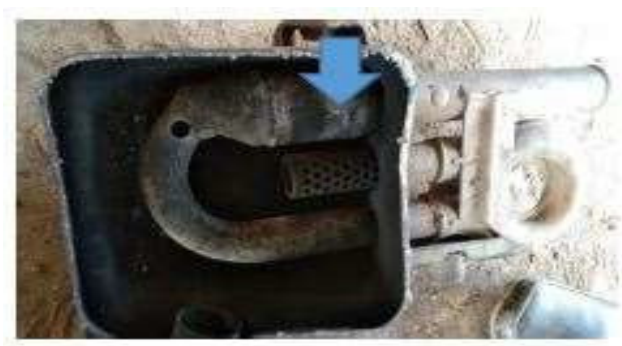

Figure 6. cut section of component

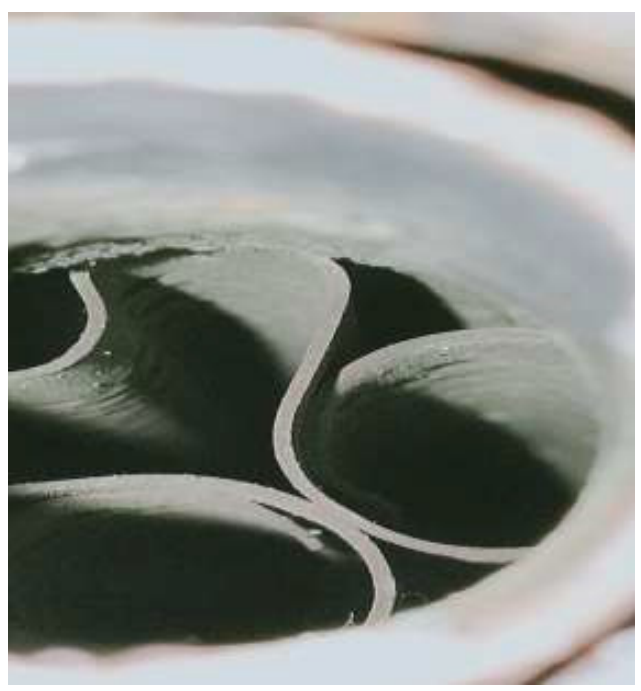

Figure 7. inner carbon filter

\section{Testing Method}

\subsection{Exhaust Gas Analyzer}

In this type of testing method, the sample of gases is trapped and will be run through the various chemicals and the chemical change will be calculated.

In NDIR a pulsating infrared beam is sent through the container and exhaust emission is tested.

In fid there will be the burner which produces ions and voltage between the burner jet and collector is calculated and exhaust emission is tested. It is quickie and accurate one.

There are two types of gas analyzer

NDIR non dispersive infrared analysis FID flame ionization detector

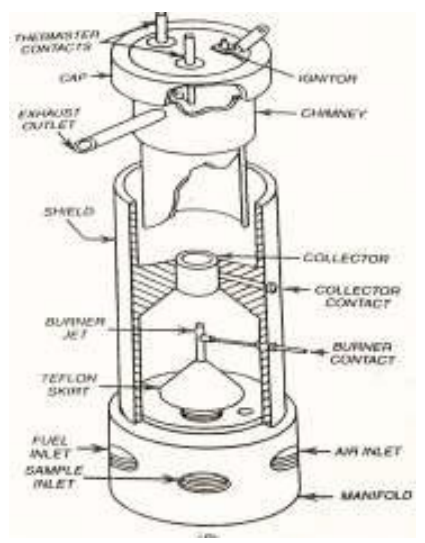

Figure 8. Gas analyzer 


\section{Result and Discussion}

\begin{tabular}{|c|c|c|c|c|c|c|c|}
\hline \multicolumn{8}{|c|}{ TEMPERATURE MEASUREMENT } \\
\hline$T$ gas & themocou ple & \multicolumn{2}{|l|}{$-10 \ldots 1000^{\circ} \mathrm{c}$} & $1^{0} \mathrm{c}$ & $\pm 2^{0} \mathrm{c}$ & $1^{0} \mathrm{c}$ & $30 \mathrm{~s}$ \\
\hline Tamb & thermiste $\mathrm{r}$ & $-10 \ldots 100^{\circ} \mathrm{c}$ & & $1^{0} \mathrm{c}$ & $\pm 1^{0} \mathrm{c}$ & $1^{0} \mathrm{c}$ & $30 \mathrm{~s}$ \\
\hline \multicolumn{8}{|c|}{ CALCULATED PARAMETERS } \\
\hline \multicolumn{2}{|l|}{ Lambda excess air number } & calculated & \multicolumn{2}{|c|}{0.01} & & & \\
\hline Qa combustion loss & \multicolumn{2}{|c|}{ calculated } & \multicolumn{2}{|c|}{$0.1 \%$} & & & \\
\hline Eta efficiency & \multicolumn{2}{|c|}{ calculated } & \multicolumn{2}{|c|}{$0.1 \%$} & & & \\
\hline \multicolumn{8}{|c|}{ MEASURED PRESSURES } \\
\hline Pressure/dra ught & DMS bridge & $-25 \mathrm{hPa} \ldots+25 \mathrm{hPa}$ & $0.1 \mathrm{~Pa}$ & \multicolumn{2}{|c|}{ $\pm 2 \mathrm{~Pa}$ or $5 \%$ rel } & $0.1 \mathrm{~Pa}$ & $10 \mathrm{~s}$ \\
\hline Ambient pressure & DMS bridge & $800 \mathrm{mbar} . .1200 \mathrm{mbar}$ & $1 \mathrm{mb}$ ar & \multicolumn{2}{|r|}{ $\pm 5 \mathrm{mbar}$ or $2 \%$ rel } & $1 \mathrm{mb}$ ar & $10 \mathrm{~s}$ \\
\hline
\end{tabular}

\begin{tabular}{|c|c|c|c|}
\hline PARAMETERS & REGULATION LIMIT & ACTUAL WITHOUT MODIFICATION & ACTUAL WITH CATALYTIC MODIFICATION \\
\hline Co (\% by Vol.) & 3.5 & 0.68 & 0.65 \\
\hline HC(ppm) & 4500 & 195 & 168 \\
\hline lambda & 14.35 & 0.02 & 0.02 \\
\hline
\end{tabular}

From the above tested exhaust gas we calculate the HC CO value of exhaust with and without the catalytic modification and also oxygen and pressure and temperature of compnent is calculated and compared.

\section{Conclution}

The improved catalytic is test under variable load and compare with without catalytic convertor system on same engine for its performance and emission parameter of CI engine.

As we combining the soot filter and selective catalytic convertor, it will satisfy our main objective i.e. low weightvolume ratio and High NOx reduction emission in high temperature. Modifying the catalytic convertor may solve the problems and the euro 6 emission norms will be satisfied.

\section{References}

Kalam, M. A., Masjuki, H. H., Redzuan, M., Mahlia, T. M. I., Fuad, M. A., Mohibah, M., ... \& Yusoff, A. (2009). Development and test of a new catalytic converter for natural gas fuelled engine. Sadhana, 34(3), 467-481.

Mohamad, I. S., Husin, M. H. M., Herawan, S. G., Hassan, M. Z., Nordin, M. R., Azelee, W., ... \& Yacob, A. R. (2009). Development of tin (IV) oxide based catalyst for carbon monoxide emission control. Journal of Mechanical Engineering and Technology (JMET), 1(1), 15-24.

Courtois, X., Perrichon, V., \& Primet, M. (2000). Three-way catalytic activity of alumina-supported copper catalysts modified by rhodium. Comptes Rendus de l'Académie des Sciences-Series IIC-Chemistry, 3(6), 429-436.

Wu, G. J., \& Song, T. (2005). CFD simulation of the effect of upstream flow distribution on the light-off performance of a catalytic converter. Energy Conversion and Management, 46(13-14), 2010-2031.

Koltsakis, G. C., \& Stamatelos, A. M. (1997). Catalytic automotive exhaust aftertreatment. Progress in Energy and Combustion Science, 23(1), 1-39.

\section{Copyrights}

Copyright for this article is retained by the author(s), with first publication rights granted to the journal.

This is an open-access article distributed under the terms and conditions of the Creative Commons Attribution license (http://creativecommons.org/licenses/by/4.0/). 